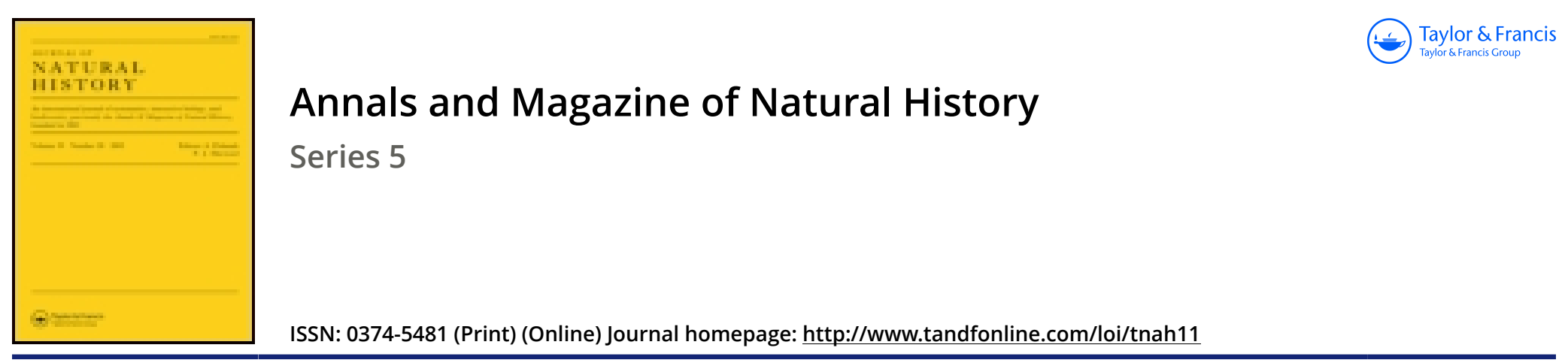

\title{
On radial and bilateral symmetry in animals
}

\section{H.W. Conn}

To cite this article: H.W. Conn (1883) On radial and bilateral symmetry in animals, Annals and Magazine of Natural History, 12:67, 69-70, DOI: 10.1080/00222938309459580

To link to this article: http://dx.doi.org/10.1080/00222938309459580

$$
\text { 曲 Published online: } 07 \text { Oct } 2009 .
$$

Submit your article to this journal $\pi$

LII Article views: 3

Q View related articles $\asymp$ 
through two successive phases: the first would correspond to the form $\mathrm{A}$; but, in consequence of the resorption of the large central chamber, the animal would construct a series of new chambers corresponding to the form $B$.

In all the species examined exact measurements have shown us that, supposing the central chamber to be absorbed, the space set free between the first serial chambers of the form $A$ is large enough to allow the modified chambers of the form $B$ to be developed.

It now remains for us, before pronouncing in favour of one of these two hypotheses, to trace a living species through all the phases of its evolution.-Comptes Rendus, May 28, 1883, p. 1598.

\section{On Radial and Bilateral Symmetry in Animals. By H. W. Cons.}

The relation of radial to bilateral symmetry among animals is a question in regard to which there has been considerable discussion. It is, however, today pretty generally acknowledged that the type of radial symmetry must have preceded that of bilateral symmetry. Two important views are current as to the origin of a bilateral form of symmetry, such as is presented by the group Vermes, from a radial symmetry, such as we find in the Coelenterata. The simplest view, of which Ray Lankester is an exponent, is as follows:-

Starting with a radially symmetrical larva, this view supposes that the two forms of symmetry arose with reference to the stationary or locomotive life of the animal. On the one hand, the stationary animal retains its primitive radial symmetry and grows into a radiate adult. On the other hand, the locomotive larva is modified by its free life. Its growth, in order to give greater freedom of motion, results in an elongation of the body in a direction parallel with its axis. Such a long cylindrical body would of necessity soon develop swimming-organs; and these swimming-organs, in order to give greater steadiness of motion and prevent an inconvenient revolution of the body, would appear in such a position as to give the animal an upper and an under surface, and consequently a bilateral symmetry. With the continued elongation of the body, the digestive tract, which at first ended blindly, also would elongate and finally acquire a posterior opening at a position directly opposite the mouth. This view, then, supposes the body of the radiate animal to elongate in the direction of its long axis, and a bilateral symmetry to arise in reference to the organs of locomotion.

A second view, advanced by Balfour, while based on the same fundamental principle of stationary and free life, supposes the change to take place in a different fashion. This view supposes that the growth of the free-living radiate form resulted in an elongation, not in the direction of the axis of the animal, but rather at right angles to this axis. This places the mouth of the animal, from the first, not at one extremity but upon one side, which therefore becomes very early the ventral side. The swimming-organs afterwards arose in reforence to the already indicated bilateral symmetry. 
These two views are fundamentally different. Bosides affecting our belief as to the manner in which bilateral symmetry arose, the acceptance of one or the other is the foundation of our understanding of the homologies which are to be fousd in the two groups.

Evidence for the one or the other of the views is to be looked for in embryology ; but very few animals give an opportunity for such research, owing to secondary changes which have acted upon the ova and the embryos. For this reason no direct evidence has been hitherto obtained. At Beaufort, during the last summer, some work was done upon Thalassema, a species of worm which possesses a very primitive development, and enables a direct study of the origin of bilateral symmetry from radial symmetry to be made. The results of the observations were satisfactory upon the point in question, and showed that, as far as this group of animals is concerned, the second of the above views, viz. that of Balfour, is in all essential respects correct. The radially symmetrical gastrula elongates nearly at right angles to its long axis, and gives rise to a bilateral larva, of which the ventral surface has been from the first indicated by the position of the mouth. The acquisition of a direct motion occurs some time after the animal is truly bilateral, an indirect revolutionary motion being gradually changed into a direct motion with its anterior extremity in advance.-Johns Hoplins University Circulars, April 1883, p. 73.

\section{Observations on Blastogenesis and Alternation of Generations in the Salpæ and Pyrosomata. By M. L. JoLrer.}

In 1868 Kowalcvsky traced with precision the principal features of the blastogenetic development of the Salpce. According to him the stolon consists, as in the Pyrosomata, of two tubes, one withiu the other, prolonging the ectoderm and endoderm of the parent. In the free space left between them run four cords-two lateral, derived from the cloaea, two median (one inferior, the othor superior), derived from two masses of mesodermic cells. According to the same author the skin, the branchio-intestinal tube, and the cloaca of each of the aggregated Salpce are derived from the corresponding parts of the stolon, and, consequently, of the parent; the nervous system and the genital organs, formed at the expense of the median cords, result from the development of two groups of mesodermic cells.

Sinco this very precise exposition three chief memoirs have appeared upon the same subject; these have again brought into question the whole problem of gemmation and alternation of generations.

Thus, according to Salensky, the inner tube as well as the lateral cords have only a transitory function: the latter are derived from the pericardium; and the intestine is formed at the expense of the inferior cord. 